\title{
OS FATORES DETERMINANTES DA INTANGIBILIDADE
}

\section{THE DETERMINANTS OF INTANGIBILITY}

EDUARDO KAZUO KAYO

Professor do Programa de Pós-Graduação em Administração de Empresas na Universidade Presbiteriana Mackenzie. Doutor e Mestre em Administração pela FEA - USP. Av. Casa Verde, 37 - São Paulo - SP - CEP 02519-000 E-mail: eduardo.kayo@mackenzie.com.br

HER B ERT KIMURA Professor do Programa de Pós-Graduação em Administração de Empresas na Universidade Presbiteriana Mackenzie. Doutor em Administração pela FEA - USP e pela EAESP - FGV. Mestre em Estatística pela IME - USP. Rua da Consolação, 896 - São Paulo - SP - CEP $01302-907$ E-mail: hkimura@mackenzie.com.br

LEONARDO FERNANDO CRUZ BASSO Professor do Programa de Pós-Graduação em Administração de Empresas na Universidade Presbiteriana Mackenzie. PhD em Economia pela New School of Social Research, Estados Unidos. Rua da Consolação, 896 - São Paulo - SP - CEP $01302-907$ E-mail: leonardobasso@mackenzie.com.br

ELIZABETH KRAUTER Doutoranda em Administração pela FEA - USP. Mestre em Administração pela Universidade Presbiteriana Mackenzie. Rua Marina Crespi, 195, ap. 2.203 - São Paulo - SP - CEP 0311 2-090 E-mail: ekrauter@usp.br 


\section{RESUMO}

O estudo dos ativos intangíveis tem despertado crescente interesse nos últimos anos. Por força dessa tendência, estudar as empresas que se utilizam intensamente desse tipo de ativo também é igualmente importante. Os ativos intangíveis são responsáveis por grandes mudanças nas características financeiras e operacionais das empresas. Partindo-se dessa suposição, uma questão importante a ser analisada é se existem diferenças significativas entre as empresas intensivas em ativos intangíveis e as empresas intensivas em ativos tangíveis. Assim, este artigo tem por objetivo identificar e analisar os possíveis determinantes econômico-financeiros da intangibilidade das empresas brasileiras. Os resultados mostram que duas variáveis, o endividamento e o tamanho, são importantes na diferenciação entre as empresas intangível-intensivas e tangívelintensivas.

\section{PALAVRAS-CHAVE}

Ativos intangíveis; Análise discriminante; Regressão logística.

\section{ABSTRACT}

The study of intangible assets has attracted increasing interest in the recent years. By force of this trend, the study of companies that intensely use this type of asset is also relevant. The intangible assets are responsible for great changes in the financial and operational characteristics of the companies. Following this assumption, an important question to be analyzed is whether significant differences between tangible-intensive and intangible-intensive companies exist. Thus, the objective of this paper is to analyze the possible financial-economic determinants of the intangibility of the Brazilian companies. The results show that two variables related to the debt level and to the size of companies are important in the differentiation between the intangible-intensive and tangible-intensive firms in Brazil. 


\section{KEYWORDS}

Intangible assets; Discriminant analysis; Logistic regression.

\section{INTRODUÇ ÃO}

A teoria de finanças preconiza que, para se calcular o valor intrínseco das empresas, o método mais adequado é o do fluxo de caixa descontado. O valor gerado, por sua vez, é resultado da combinação dos valores de ativos tangíveis e intangíveis. Em geral, o processo de valoração de empresas (especialmente para fins de fusões e aquisições) não considera a divisão do valor em seus componentes tangíveis ou intangíveis. Afinal, em um processo de fusão ou aquisição, o valor negociado, normalmente, diz respeito à empresa como um todo.

Entretanto, a valoração de empresas não é realizada apenas para esta finalidade. Além da finalidade de negociação, a valoração também é importante para fins de gestão. Nesse caso, passa a ser importante desagregar o valor da empresa e se conhecer o valor de cada tipo de ativo, seja tangível ou intangível. O maior desafio estratégico da gestão financeira é a maximização desses valores de forma que a riqueza do proprietário da empresa também seja maximizada.

O estudo dos ativos intangíveis não é um fenômeno recente, mas tem despertado um crescente interesse das comunidades acadêmica e de negócios nos últimos anos. Isso se deve, principalmente, ao esforço das empresas em se diferenciarem de seus concorrentes. À medida que as empresas têm acesso relativamente fácil à aquisição de ativos tangíveis (terrenos, edifícios, máquinas, equipamentos etc.), o que passa a diferenciar umas das outras é a sua carteira de ativos intangíveis, cuja principal característica é a singularidade.

Nas últimas décadas, os intangíveis têm promovido grandes mudanças nas características financeiras e operacionais das empresas. Com base nisso, é possível classificar as empresas por categorias de intangibilidade: intangível-intensivas e tangível-intensivas. Uma questão importante a ser resolvida é descobrir se existem diferenças significativas entre as características dessas duas empresas e, dessa forma, adotar modelos de gestão que sejam mais eficazes para cada uma delas.

Diversas pesquisas no exterior (CHAUVIN; HIRSCHEY, I993; MEGNA; KLOCK, I993; VILLALONGA, 2004; entre outros) e também no Brasil (KAYO; TEH; KIMURA, 2005; PEREZ; FAMÁ, 2006; entre outros) têm estudado a influência de ativos intangíveis sobre o desempenho das empresas. Se, por um lado, muitos esforços têm sido empreendidos para se entender a influência dos intangíveis sobre a criação de valor, por outro lado é fundamental se conhecer também o que determina essa intangibilidade. 
Nesse contexto, o problema de pesquisa que se procura responder é: Quais os determinantes da intangibilidade das empresas brasileiras? Nesse enfoque, o principal objetivo do artigo é identificar possíveis determinantes econômico-financeiros da intangibilidade das empresas brasileiras e analisar a relação entre essas variáveis. Para tanto, são aplicadas especificamente duas técnicas de estatística multivariada: a análise discriminante e a regressão logística. Essas técnicas são adequadas na análise das relações entre variáveis dependentes categóricas e variáveis independentes métricas e/ou categóricas. Neste artigo, a variável dependente é o nível de intangibilidade, que assume duas categorias: intangívelintensiva ou tangível-intensiva.

Os resultados da pesquisa sugerem que duas variáveis podem ser importantes para explicar a intangibilidade das empresas: o endividamento e o tamanho. O endividamento apresenta uma relação negativa e o tamanho uma relação positiva com a variável dependente. Isto é, empresas maiores e com menos dívidas têm maior probabilidade de serem intangível-intensivas.

\section{REFERENCIAL TEÓRICO}

\subsection{ATIVOS INTANGíVEIS E CRIAÇÃO DE VALOR}

As últimas décadas do século XX mostram evidências de uma crescente importância dos ativos intangíveis. Reflexo disso é o crescimento do índice valor de mercado/valor contábil (market-to-book ratio), que pode ser considerado um indicador do nível de intangibilidade das empresas. De acordo com Lev (200I), esse índice médio das empresas relacionadas no S\&P 500 subiu de um, no início da década de I980, para seis, em 200I. Isso não significa que esses ativos não existiam. De fato, eles existiam, mas os investidores passaram a dar mais valor a eles. Essa maior valorização tem levado os gestores a se preocuparem com ativos intangíveis antes subvalorizados, como a marca.

Do ponto de vista estratégico, a gestão apropriada dos ativos intangíveis exerce um papel fundamental no desempenho sustentável e na formação do valor econômico de uma empresa. Com efeito, várias pesquisas têm apresentado evidências de que os ativos intangíveis são importantes fontes de criação de valor. Chauvin e Hirschey (I993), analisando a influência das despesas com pesquisa e desenvolvimento (importantes geradoras de ativos intangíveis) sobre o valor de mercado de empresas norte-americanas, encontram uma relação positiva e significante entre essas variáveis. Em outra pesquisa, Megna e Klock (I993) analisam duas variáveis relacionadas a ativos intangíveis, quantidade de patentes e despesas com pesquisa e desenvolvimento, verificando uma influência 
positiva dessas variáveis em relação ao Q de Tobin das empresas analisadas. No Brasil, Kayo, Teh e Kimura (2005) não encontram evidências de que a quantidade de patentes influencie positivamente a criação de valor. Eles argumentam que esse resultado pode ser reflexo, entre outros fatores, do baixo nível de investimento em inovação promovido pelas empresas brasileiras. A marca é outro ativo intangível muito pesquisado. Chauvin e Hirschey (I993) acham evidências de que as despesas com publicidade, proxy para o valor das marcas, exercem um efeito positivo sobre a criação de valor. No Brasil, de forma semelhante, Kayo, Teh e Kimura (2005) encontram evidências de que a quantidade de marcas é positivamente relacionada com a criação de valor.

Para se definir ativos intangíveis, é preciso que se entenda, em primeiro lugar, o que é ativo. Uma definição adequada de ativo parece ser fundamentada em termos econômicos. A definição de Martins (I972, p. 30), que se baseia nisso, conceitua ativo como sendo "o futuro resultado econômico que se espera obter de um agente". Esse conceito é consistente com o método do fluxo de caixa descontado, pelo qual o valor de um ativo (ou capital) é obtido pela soma dos fluxos de caixa futuros, descontados a uma taxa apropriada ao seu nível de risco (COPELAND; KOLLER; MURRIN, I996). Nesse contexto, Lev (200I) define ativo intangível como um direito a benefícios futuros que não possui corpo físico ou financeiro (ações ou títulos de dívida).

Por esse ponto de vista econômico, um ativo, seja tangível ou intangível, vale pelo que é capaz de gerar no futuro. Sendo assim, as estratégias definidas pela empresa afetam positiva ou negativamente a valorização das empresas.

\section{ATIVOS INTANGÍVEIS E SUAS IMPLICAÇÕES MICROECONÔMICAS}

Do ponto de vista econômico, segundo Lev (200I), os ativos intangíveis apresentam duas importantes características: não-rivalidade e capacidade de escala. A não-rivalidade dos intangíveis diz respeito à capacidade de serem utilizados simultaneamente de diversas formas diferentes. A utilização de um ativo intangível não o impede de ser aplicado a um uso alternativo ao mesmo tempo. Entretanto, os ativos tangíveis não podem ser utilizados ao mesmo tempo em situações diferentes. Uma máquina não pode fabricar dois produtos diferentes simultaneamente, assim como uma plataforma de petróleo não pode estar em dois locais diferentes ao mesmo tempo. A utilização dos ativos tangíveis é limitada por sua capacidade de produção ou por outras limitações físicas.

Segundo Lev (200I), os ativos intangíveis são limitados apenas pelo tamanho do mercado. Não existe limitação física para a utilização de um ativo intangível. Uma marca conhecida e respeitada mundialmente, por exemplo, pode ex- 
pandir seu mercado por meio do seu licenciamento a uma empresa que se responsabilizaria pela fabricação e comercialização do produto sem a necessidade da proprietária da marca se imobilizar.

Segundo Lev (200I), a empresa tradicional, verticalmente integrada e capital-intensiva, é desenhada para explorar economias de escala. À medida que essas economias de escala se exaurem, a produção se transforma em simples commodity e a empresa não consegue mais sustentar seu crescimento e suas vantagens competitivas.

De acordo com Lev (200I), a tradicional economia de escala pode ser complementada e, às vezes, substituída pelo fenômeno da externalidade de rede. Externalidades de rede surgem quando "a demanda exercida por uma pessoa pode vir a ser influenciada pelo número de outros consumidores que já tenham adquirido a mercadoria" (PINDYCK; RUBINFELD, I994, p. I50). As externalidades podem ser positivas ou negativas. Nas positivas, também conhecidas por "efeito imitação" (PINDYCK; RUBINFELD, I994, p. 50), há um aumento da quantidade demandada quando outros consumidores adquirem a mesma mercadoria (exemplos típicos são os programas de computador, os próprios computadores, as fitas de vídeo VHS, o crescente uso do DVD etc.). Nesse caso, os benefícios de se fazer parte de uma rede é maior, quanto maior for o número de pessoas ou empresas que façam parte da mesma. Nas externalidades negativas, também conhecidas por "efeito esnobação" (PINDYCK; RUBINFELD, I994, p. I53), acontece o contrário, ou seja, a quantidade diminui quando muitos consumidores adquirem o produto (como é o caso de produtos muito luxuosos).

Essas questões econômicas têm implicações importantes na avaliação e gestão dos ativos intangíveis. Tome-se, por exemplo, a gestão da identidade da marca, um dos intangíveis mais importantes da empresa. Identidade da marca, como define Aaker e Joachimsthaler (2000, p. 40), é "uma série de associações que o estrategista de marca procura criar e manter". Essas associações são permeadas por uma série de valores (como qualidade, inovação etc.) que a organização deseja ter e transmitir a seus consumidores. Para esses autores, se algum elemento importante do trabalho de identidade da marca estiver ausente é improvável que a marca alcance todo o seu potencial. O desenvolvimento da cultura, dos princípios e dos valores da empresa deve ser acompanhado do pleno conhecimento do público consumidor que se quer atingir. Para isso, conhecer os efeitos de externalidades de rede é muito importante. A partir desse ponto, a empresa tem condições de dimensionar os investimentos necessários no capital tangível e intangível.

\section{2 - 3 A AVALIAÇÃO DOS INTANGÍVEIS}

A avaliação dos ativos intangíveis é um processo importante por várias razões. Ela pode, por exemplo, servir de base para uma operação de fusão ou aqui- 
sição. Também pode servir como sustentação para operações de securitização ou garantias de empréstimos, como sugerem Reilly e Schweihs (I999). Entretanto, um dos motivos mais importantes da avaliação é sua utilização para a gestão estratégica dos ativos intangíveis.

O processo de gestão é facilitado quando se sabe o valor do que se quer gerir. A gestão de caixa, do imobilizado, entre outros ativos tangíveis, é relativamente fácil porque tais ativos já possuem um valor estabelecido ex-ante. À medida que são atribuídos valores também aos intangíveis, o seu processo de gestão também é facilitado.

Para o processo de avaliação dos intangíveis, um dos métodos que pode ser aplicado é o EVA ${ }^{\circledR}$ - economic value added, ou valor econômico adicionado - como proposto por Stewart III (I999). O conceito do EVA é semelhante ao do lucro residual, como sugere Rappaport (I998). O lucro residual, ou residual income, inicialmente proposto pela General Electric em I950, é definido como o "lucro operacional líquido depois dos impostos (NOPAT) menos um encargo sobre o capital investido" (RAPPAPORT, I998, p. I2I).

Quando se trata da avaliação dos intangíveis pelo método do EVA, três questões importantes devem ser consideradas: I) projeção dos resultados econômico-financeiros; 2) identificação e separação dos ativos tangíveis e intangíveis; e 3) custo de capital apropriado a cada tipo de ativo.

O primeiro passo na projeção dos resultados econômico-financeiros é o cálculo do valor econômico adicionado. O EVA, segundo Stewart III (I999), é a diferença entre os lucros que a empresa obtém de suas operações e o custo incorrido pelo uso do capital, como mostra a equação I.

$$
\mathrm{EVA}=\mathrm{NOPAT}-c^{*} \mathrm{x} \text { capital }
$$

\section{Equação I}

em que:

NOPAT = lucro operacional líquido depois do imposto de renda

$c^{*} \quad=$ custo do capital

capital = capital tangível total, ou seja, ativo imobilizado e capital de giro operacional

O MVA, por sua vez, resulta da soma de todos os EVAs projetados e trazidos a valor presente por uma taxa de desconto adequada. O valor do MVA, que é a diferença entre o valor de mercado da empresa e o capital tangível, equivale ao valor dos ativos intangíveis.

O passo seguinte na avaliação dos ativos intangíveis é a identificação e separação, em primeiro lugar, dos ativos tangíveis dos intangíveis e, em segundo lugar, dos vários tipos de intangíveis. A separação entre tangíveis e intangíveis já 
é contemplada no cálculo do EVA em função da subtração do custo sobre a utilização do capital tangível. Mesmo assim, é complexo definir os limites entre o que é tangível e o que é intangível.

Ainda mais complexa é a separação dos diversos tipos de intangíveis. Essa é uma tarefa bastante subjetiva. Uma das formas de se resolver essa questão é por meio da análise de direcionadores que contribuem para a geração do valor adicionado, mas essa questão não faz parte do escopo deste ensaio.

Depois que os resultados econômico-financeiros são projetados e as contribuições de cada ativo intangível são conhecidas, o passo final é trazer a valor presente, por uma taxa de desconto adequada, os resultados atribuídos a cada tipo de intangível. A conclusão dessas três fases deve gerar o valor de cada ativo intangível.

A forma como uma empresa gerencia seus ativos intangíveis pode definir a formação do seu valor intrínseco. Essa gestão, por sua vez, deve levar em consideração as características peculiares das empresas intangível-intensivas. Para que a gestão seja adequada e eficaz, é preciso se conhecer o que diferencia um tipo de empresa de outro.

\section{METOdOLOGIA dA PESQUISA}

\section{1 PROBLEMA DE PESQUISA E OBJETIVO}

Como demonstrado no referencial teórico, várias pesquisas no Brasil e principalmente no exterior têm mostrado que os ativos intangíveis exercem um papel importante na criação de valor das empresas. Portanto, nesses estudos, os ativos intangíveis, por meio de suas variáveis proxy, eram estudados como variáveis independentes. A motivação para a presente pesquisa foi analisar a intangibilidade, ao contrário dos referidos estudos, como variável dependente. Assim, o problema de pesquisa que se procura responder é: Quais os determinantes da intangibilidade das empresas brasileiras?

Nesse contexto, o principal objetivo do artigo é identificar possíveis determinantes econômico-financeiros da intangibilidade das empresas brasileiras e analisar a relação entre essas variáveis.

\section{2 LEVANTAMENTO DOS DADOS}

Os dados necessários para a realização da pesquisa são levantados a partir de uma fonte secundária: a Economática. Com a intenção de se obter o maior número possível de observações, consideram-se os dados econômico-financeiros de $200 \mathrm{I}$ das empresas brasileiras listadas na base de dados da Economática. 
Nesta pesquisa, são excluídos os setores Bancos e Finanças e Fundos em função das regulamentações e peculiaridades específicas destes setores. Apenas empresas industriais e comerciais são analisadas. Algumas empresas não apresentam todas as variáveis necessárias para a realização das análises estatísticas. Nesse caso, essas variáveis são estatisticamente consideradas como missing values e o tratamento estatístico é abordado mais adiante.

\section{3 OPERACIONALIZAÇÃO DAS VARIÁVEIS}

Para a construção da matriz de dados, são operacionalizadas, para cada uma das empresas, as variáveis relevantes para a análise, que podem ser visualizadas de forma resumida a seguir, em que o valor de mercado equivale ao valor das ações negociadas em bolsas de valores.

\section{TABELA I}

\begin{tabular}{clcl} 
& & RESUMO DAS VARIAVEIS E RESPECTIVAS DESCRIÇÖES \\
\hline TIPO & PERSPECTIVA & VARIÁVEL & \multicolumn{1}{c}{ DESCRIÇÃO RESUMIDA } \\
\hline Métrica & Risco & beta & Nível de risco sistemático \\
Métrica & Crescimento & cresat & Crescimento do ativo total \\
Métrica & Endividamento & endiv & Endividamento em relação ao valor de mercado \\
Métrica & Liquidez & liqcor & Liquidez corrente \\
Métrica & Rentabilidade & rct & Retorno sobre o capital total \\
Métrica & Tamanho & tamvm & Valor de mercado \\
Métrica & Intangibilidade & intang & Índice de intangibilidade \\
Categórica & Intangibilidade & C_int & Categoria de intangibilidade \\
\hline
\end{tabular}

O nível de risco das empresas analisadas é representado pelo beta, do modelo CAPM. O beta utilizado na pesquisa é o disponibilizado pela Economática e sua fórmula é apresenta pela equação 2 .

$$
\beta_{\mathrm{i}}=\frac{\sigma_{\mathrm{iM}}}{\sigma_{\mathrm{M}}^{2}}
$$

\section{Equação 2}

em que :

$\sigma_{\mathrm{iM}}=$ covariância entre o retorno do ativo i e do índice de mercado

$\sigma_{\mathrm{M}}^{2}=$ variância de retornos do índice de mercado

O crescimento do ativo total é calculado pela evolução do ativo total de um ano em relação ao ano imediatamente anterior, como mostra a equação 3. 


$$
\text { cresat }=\frac{\mathrm{ATC}_{\mathrm{t}}}{\mathrm{ATC}_{\mathrm{t}-1}}-1
$$

Equação 3

em que:

$$
\begin{aligned}
& \mathrm{ATC}_{\mathrm{t}}=\text { ativo total contábil do ano } \mathrm{t} \\
& \mathrm{ATC}_{\mathrm{t}-1}=\text { ativo total contábil do ano } \mathrm{t}-1
\end{aligned}
$$

O grau de endividamento das empresas analisadas contempla, tão-somente, as dívidas financeiras, de curto e longo prazos, contraídas por debêntures, financiamentos bancários diversos e adiantamentos de contratos de câmbio. Empréstimos de curto prazo relacionados ao capital de giro não são incluídos como dívidas financeiras. Essa variável é calculada pela relação dessas dívidas com o valor de mercado total das ações, como mostra a equação 4 .

$$
\text { endiv }=\frac{\mathrm{DFT}}{\mathrm{VM}}
$$

Equação 4

em que:

$\mathrm{DFT}=$ dívidas financeiras totais

$\mathrm{VM}=$ valor de mercado total das ações

A fórmula tradicional para o cálculo da liquidez corrente é mostrada na equação 5. Esse índice representa a potencial disponibilidade de recursos de curto prazo para a quitação das dívidas operacionais também de curto prazo. Em primeira análise, uma liquidez alta pode representar segurança aos públicos estratégicos (stakeholders) da empresa. No entanto, recursos disponíveis (especialmente caixa e aplicações financeiras) em excesso evidenciados por uma liquidez alta podem indicar a falta de projetos de investimento, o que pode comprometer o crescimento futuro.

$$
\text { liqcor }=\frac{\mathrm{AC}}{\mathrm{PC}}
$$

\section{Equação 5}

em que:

$$
\begin{aligned}
& \mathrm{AC}=\text { ativo circulante } \\
& \mathrm{PC}=\text { passivo circulante }
\end{aligned}
$$

Para o indicador de rentabilidade, toma-se uma variação da fórmula tradicional de retorno sobre o ativo à medida que o índice utiliza, no denominador, o valor de mercado e não o valor contábil da empresa. Procura-se, assim, mostrar a eficiência na geração de lucros tanto dos ativos tangíveis quanto intangíveis. 


$$
\mathrm{rct}=\frac{\mathrm{LL}}{\mathrm{VMF}}
$$

Equação 6

em que:

LL = lucro líquido

$\mathrm{VMF}=$ valor de mercado da firma

O tamanho da empresa é representado por uma função do valor de mercado das ações. Para fins de eliminação de uma dispersão elevada da perspectiva relacionada ao tamanho, utilizou-se o logaritmo neperiano do valor de mercado das ações.

$$
\operatorname{tamvm}=\ln (\mathrm{VM})
$$

Equação 7

em que:

$\mathrm{VM}=$ valor de mercado total das ações

Já para o cálculo da variável intang, utiliza-se procedimento semelhante ao do índice valor de mercado/valor contábil, como mostra a equação a seguir. Dessa forma, assume-se que, quanto maior esse índice, maior é a participação dos ativos intangíveis no valor das empresas.

$$
\text { int ang }=\frac{\mathrm{VM}}{\mathrm{PLC}}
$$

Equação 8

em que:

PLC = patrimônio líquido contábil

A intensidade em ativos intangíveis (c_int) é uma variável categórica que divide as empresas em duas subamostras. A variável métrica intang serve de base para essa divisão. As empresas a serem classificadas como tangível-intensivas apresentam valor o e as empresas a serem classificadas como intangívelintensivas o valor I.

\section{RESULTADOS DA ANÁLISE ESTATÍSTICA}

Para a aplicação de técnicas multivariadas, é importante que seja realizada uma avaliação preliminar dos dados amostrais visando a uma melhor adequação da amostra às premissas dos modelos estatísticos. Observa-se inicialmente que 
os dados faltantes na amostra não são gerados por um processo aleatório, por pelo menos dois motivos: um mesmo dado é utilizado para calcular diferentes indicadores financeiros e o procedimento de atualização da base de dados pode influenciar dados faltantes de diversas empresas de uma forma sistemática. Desta maneira, para evitar problemas de relacionamento entre dados faltantes optase pela eliminação de observações que apresentavam pelo menos um missing value, fazendo com que a amostra totalizasse i 62 empresas.

A seguir, analisa-se a existência de outliers na amostra. Apesar de desvios extremos em relação a variáveis individuais não representarem indícios fortes de outliers em análises multivariadas, decide-se nesta pesquisa pela utilização de critérios menos conservadores. Por isso, estabelece-se a exclusão de observações cujos dados se distanciam mais de três desvios padrões da média amostral, em pelo menos uma das variáveis relevantes. Com este procedimento, a amostra é reduzida para um total de 150 empresas.

Neste estudo, o indicador de intangibilidade é utilizado para classificar empresas tangível-intensivas das empresas intangível-intensivas. Obviamente, esta classificação envolve um certo subjetivismo, principalmente em função da necessidade de estabelecimento de um valor arbitrário para segregar os dois tipos de empresa. Para diminuir o impacto da arbitrariedade, opta-se por eliminar empresas cujo índice de intangibilidade estivesse próximo a um valor médio, uma vez que teriam maior probabilidade de classificação inadequada.

Considerando que o índice de intangibilidade tem uma distribuição normal entre a população das empresas brasileiras, decide-se arbitrariamente eliminar observações com índices próximos à média amostral, pois a característica de tangibilidade ou intangibilidade destas companhias não são muito pronunciadas. Para isto, utiliza-se o desvio padrão amostral como estimador do desvio padrão da população, estabelecendo como limite para exclusão uma distância inferior a aproximadamente 0,125 desvios padrões em relação à média, que implica em uma eliminação teórica de cerca de I0\% das observações. Na prática, este procedimento acarreta a eliminação de 32 observações, pois a distribuição do índice de intangibilidade na amostra mostra-se leptocúrtica. Finalmente, a análise das observações restantes sugere uma concentração maior de empresas caracterizadas como tangível-intensivas. Das II7 observações da amostra final, 32 são classificadas como intangível-intensivas e 85 são classificadas como tangível-intensivas.

A partir da classificação realizada, procede-se à realização de testes estatísticos para identificar possíveis indicadores financeiros que poderiam estar associados ao tipo de empresa com relação à intangibilidade.

Primeiramente, procede-se ao teste $t$ de igualdade de médias. Os testes de igualdade entre médias possibilitam avaliar a hipótese de duas amostras diferentes representarem duas populações com os mesmos valores médios. Se os 
resultados dos testes forem significantes, pode-se inferir uma alta probabilidade de que as amostras estão associadas a populações de diferentes médias. No caso específico desta pesquisa, diferenças entre médias podem sugerir que empresas tangível-intensivas e intangível-intensivas têm características financeiras distintas.

Apesar da premissa de normalidade do teste ser violada pelos dados da amostra, este procedimento possibilita uma primeira avaliação dos determinantes de intangibilidade. A tabela a seguir mostra os resultados do teste de igualdade de médias, em que a diferença positiva indica que a média das empresas consideradas tangível-intensivas é maior do que a média das empresas intangível-intensivas e vice-versa. Ou seja, a diferença negativa indica que a média das empresas tangível-intensivas é menor do que a das empresas intangível-intensivas. Deve-se destacar que os resultados do teste não paramétrico de Mann-Whitney corroboram os resultados do teste $t$.

\section{TABELA 2}

RESULTADOS DO TESTE T DE IGUALDADE DE MÉDIAS

\begin{tabular}{lccc}
\hline INDICADOR & DIFERENÇA & ESTATÍSTICA T & SIGNIFICÂNCIA \\
\hline Endividamento & 1,13 & 4,14 & 0,00 \\
Risco & $-0,18$ & $-1,89$ & 0,07 \\
Liquidez & $-0,09$ & $-0,35$ & 0,73 \\
Retorno & $-2,82$ & $-0,77$ & 0,45 \\
Crescimento & $-0,06$ & $-1,41$ & 0,16 \\
Tamanho & $-2,52$ & $-6,87$ & 0,00 \\
\hline
\end{tabular}

A partir dos resultados anteriores, surgem evidências de que, ao nível de I\% de significância, pode-se rejeitar a hipótese de igualdade entre as médias do indicador de endividamento de empresas tangíveis e de empresas intangíveis intensivas. O mesmo vale para o indicador de tamanho da empresa. O sinal das diferenças indica que empresas menos endividadas e com mais ativos são mais propensas a serem intangível-intensivas. Em contrapartida, empresas mais endividadas e com menores valores de mercado são mais propensas a serem tangível-intensivas.

Considerando a possibilidade de existência de colinearidade entre os indicadores, procedeu-se à análise de correlação entre as variáveis independentes. Pode-se estabelecer que, considerando o nível de significância de I\%, o número de observações e a magnitude da correlação, tamanho e risco, bem como tamanho e crescimento dos ativos possuem correlações relevantes. Apesar disso, a 
correlação entre estes dois conjuntos de variáveis independentes é de apenas 0,3 e 0,2 , respectivamente.

Dados os baixos valores de correlação, procedeu-se à análise discriminante e decidiu-se utilizar todas as variáveis independentes levantadas no estudo. A análise discriminante é uma técnica estatística apropriada para se testar a hipótese de igualdade entre os valores médios de um conjunto de variáveis independentes calculados para dois ou mais grupos. A análise envolve a derivação de uma combinação linear entre várias variáveis independentes que melhor discriminam grupos definidos a priori (HAIR et al., I998).

A soma de cada variável independente multiplicada por um peso correspondente, obtido a partir dos coeficientes da análise discriminante, representa o Zscore para cada caso. Cada grupo possui um escore médio, ou centróide, que indica o valor mais provável do Z-score de qualquer observação pertencente ao grupo. Desta maneira, a análise discriminante possibilita encontrar uma função que melhor possibilita a segregação de grupos a partir da distância dos centróides e, evidentemente, do grau de dispersão dos Z-scores.

A comparação de médias realizada na etapa anterior possibilita a identificação das variáveis em que os grupos diferem significativamente. A análise discriminante permite uma certa hierarquização da importância de cada variável para fins de separação das empresas tangível-intensivas e das empresas intangível-intensivas. Considerando-se todo o conjunto de variáveis levantado na coleta de dados, é provável que apenas algumas poucas variáveis sejam suficientes para a obtenção de uma função que permita segregar razoavelmente os dois grupos de empresas.

Uma vez que, na pesquisa conduzida, a variável dependente é categórica, na qual o valor o denota as empresas tangível-intensivas e o valor I representa as empresas intangível-intensivas, e que as variáveis financeiras são métricas, a análise discriminante pode ser utilizada. Foi adotado o procedimento de step-wise, em que o F para inclusão da variável foi definido em I,25 e o F para remoção, em I,००. Estes valores de F, mais generosos, são comuns em análise discriminante (GEORGE; MALLERY, 2000). Utilizando os mesmos dados amostrais, foram obtidos os resultados descritos a seguir:

TABELA 3A

RESULTADOS DA ANÁLISE DISCRIMINANTE

\begin{tabular}{cc}
\hline TIPO DE EMPRESA & CENTRÓIDES \\
\hline Tangível & $-0,384$ \\
Intangível & 1,021 \\
\hline
\end{tabular}




\section{TABELA 3B}

\section{RESULTADOS DA ANALISE DISCRIMINANTE}

\begin{tabular}{lccc}
\hline INDICADOR & COEFICIENTES & \multicolumn{2}{c}{ LAMBDA DE WILKS } \\
& & VALOR & SIGNIFICÂNCIA \\
\hline Tamanho & 0,92 & 0,73 & 0,00 \\
Endividamento & $-0,26$ & 0,71 & 0,00 \\
\hline
\end{tabular}

Por meio da análise efetuada, considerando o lambda de Wilks, pode-se identificar novamente que as variáveis relativas ao tamanho e ao endividamento são discriminantes das empresas. A função discriminante tem significância ao nível de I\% e a correlação canônica equivale a o,534, indicando que cerca de $28,5 \%$ da variância da variável dependente é explicada pelo modelo discriminante. Os centróides definidos (Tabela 3a) e os coeficientes (Tabela 3b) implicam que empresas com menor endividamento e maior valor de mercado das ações têm maior probabilidade de serem intangível-intensivas, corroborando os resultados do teste de igualdade de médias.

Finalmente, para completar a análise estatística, realiza-se uma regressão logística. Quando a variável dependente é não-métrica e está dividida em apenas dois grupos, a regressão logística é preferível à análise discriminante devido a uma série de fatores. A regressão logística não depende das premissas extremamente restritivas sobre normalidade multivariada e igualdade das matrizes de variância e covariância entre os grupos. Além disso, a regressão logística é similar à análise de regressão, possuindo testes estatísticos diretos, habilidade de incorporar efeitos não-lineares e vários mecanismos de diagnóstico (HAIR et al., I998).

A regressão logística permite que sejam estimadas, a partir de uma única equação semelhante à equação de regressão múltipla, as probabilidades de um evento ocorrer ou não ocorrer. Dependendo de a probabilidade de ocorrência de um evento ultrapassar ou não o,50, o procedimento da regressão estabelece que a observação deve ser incluída em um ou outro grupo. Ressalta-se novamente que se optou pela inclusão de todas as variáveis independentes, dadas as baixas correlações encontradas entre elas.

Realizando a regressão logística, considerando todos os índices simultaneamente, obtêm-se os seguintes resultados: 


\section{TABELA 4}

RESULTADOS DA REGRESSAO LOGISTICA

\begin{tabular}{lcccc}
\hline INDICADOR & COEFICIENTE & Z & SIGNIFICÂNCIA & RAZÃO DAS CHANCES \\
\hline Constante & $-9,16$ & $-3,74$ & 0,00 & - \\
Endividamento & $-0,91$ & $-2,17$ & 0,03 & 0,4 \\
Risco & 0,06 & 0,08 & 0,94 & 1,06 \\
Liquidez & $-0,19$ & $-0,68$ & 0,50 & 0,83 \\
Retorno & $-0,02$ & $-1,11$ & 0,27 & 0,98 \\
Crescimento & 0,54 & 0,44 & 0,66 & 1,72 \\
Tamanho & 0,72 & 3,86 & 0,00 & 2,06 \\
\hline
\end{tabular}

Mais uma vez, os indicadores relevantes para segregar empresas quanto à intangibilidade são o tamanho e o endividamento se estabelecermos um nível de significância de 5\%. A razão das chances e a significância do indicador de tamanho da empresa sugerem, reiterando os resultados das análises estatísticas anteriores, que empresas maiores e com menos dívida têm maior probabilidade de serem intangível-intensivas. De fato, as razões das chances das perspectivas relacionadas ao endividamento e ao tamanho diferem significativamente da unidade.

Com relação aos testes de aderência, não há evidências que suportam a afirmação de que o modelo não adere adequadamente aos dados, tendo em vista a significância estimada entre 0,3I2 e 0,90I.

\section{TABELA 5}

\begin{tabular}{lrcc} 
& RESULTADOS DOS TESTES DE ADERENCIA & \\
\hline \multicolumn{1}{c}{ MÉTODO } & QUI-QUADRADO & GRAUS DE LIBERDADE & SIGNIFICÂNCIA \\
\hline Pearson & 116,744 & 110 & 0,312 \\
Deviance & 91,401 & 110 & 0,901 \\
Hosmer-Lemeshow & 7,954 & 8 & 0,438 \\
\hline
\end{tabular}

Adicionalmente, as medidas de associação, cujo intervalo do valor absoluto situa-se entre o e I, indicam, na maioria dos casos, uma habilidade de predição não muito elevada, apesar da significância dos resultados. Porém, tendo em vista a característica eminentemente qualitativa da pesquisa, deve-se ressaltar que a regressão permite a identificação de características discriminantes relevantes entre os grupos de empresas. 
TABELA 6

MEDIDAS DE ASSOCIACAOO

\begin{tabular}{lc}
\hline MEDIDA & VALOR \\
\hline D de Somers & 0,73 \\
Goodman-Kruskal Gamma & 0,73 \\
Tau-a de Kendall & 0,29 \\
\hline
\end{tabular}

Todos os testes estatísticos, considerando o teste de igualdade de médias, a análise discriminante e a regressão logística, mostram que o tamanho do valor de mercado dos ativos e o grau de endividamento da empresa são fatores discriminantes das empresas tangível-intensivas e das empresas intangível-intensivas.

\section{CONSIDERAÇÕES FINAIS}

O principal objetivo deste artigo é a análise dos determinantes de intangibilidade que é de extrema importância, principalmente em razão da crescente influência dos ativos intangíveis sobre o valor das empresas. A influência desse tipo de ativo pode afetar a forma como as empresas são geridas. Assim, para uma adequada gestão empresarial, é importante saber o que diferencia uma empresa intensiva em ativos intangíveis de outra que seja intensiva em ativos tangíveis.

Todas as análises estatísticas processadas neste artigo mostram que as variáveis endividamento e tamanho são de grande importância na diferenciação entre empresas intangível-intensivas e tangível-intensivas. Embora as limitações metodológicas deste artigo não permitam que esses resultados sejam conclusivos, eles podem ser muito sugestivos.

Um dos resultados mais importantes é a grande significância estatística do endividamento. As empresas intangível-intensivas apresentam, em média, um grau de endividamento mais baixo. Entre outras conseqüências, isso pode influenciar a formação do custo de capital. À medida que o nível de endividamento é menor, o custo médio ponderado de capital das empresas intangível-intensivas pode ser maior, já que existiria a predominância de capital próprio.

Deve-se ressaltar que os métodos multivariados utilizados supõem a existência de uma causalidade, na qual a intangibilidade pode ser determinada pela gestão financeira, caracterizada pelos níveis dos indicadores financeiros. Porém, em termos práticos, o estudo sugere que um ponto importante a ser investigado envolve possíveis relações de causa e efeito. Por exemplo, dada a própria natureza dos ativos intangíveis, comumente de difícil avaliação e sujeitos a maio- 
res riscos, credores podem estar menos motivados a emprestar dinheiro para empresas intangível-intensivas.

Assim, apesar de a metodologia empregada implicar resultados que sugerem o endividamento como variável relevante para categorizar empresas quanto à sua tangibilidade, o contrário poderia ser também uma explicação razoável. Ou seja, a característica de tangibilidade poderia explicar o nível de endividamento das empresas, uma vez que empresas intangível-intensivas teriam menor acesso a capital de terceiros, dado o maior risco identificado pelo credor.

A alta significância da variável tamanho é igualmente sugestiva. Os resultados indicam que quanto maior o tamanho, em termos de valor de mercado, maior a probabilidade da empresa em ser intangível-intensiva. Esse resultado tem relação com as questões relacionadas à capacidade de escala da empresa. A partir de um determinado tamanho, a única forma da empresa crescer passa a ser por meio do investimento em ativos intangíveis. Como sugere Lev (200I), os ativos tangíveis possuem capacidade de produção limitada, mas os intangíveis são limitados apenas pelo tamanho do mercado.

Deve-se destacar ainda que, em função do número reduzido de empresas com informações disponíveis para a realização do estudo, não foi possível o estudo de outras variáveis associadas com intangibilidade. Por exemplo, tipo de atividade, setor de atuação, entre outros fatores, constituiriam variáveis de controle importantes, que poderiam conduzir a resultados mais significantes do ponto de vista estatístico e mais específicos do ponto de vista de gestão.

Além disso, também não foi possível, dada a limitação dos dados, identificar o relacionamento de variáveis financeiras com componentes de intangibilidade e, mais ainda, a direção da causalidade da relação. Por exemplo, um dos resultados da pesquisa sugere que quanto maior o tamanho da empresa, maior sua probabilidade de ser intangível-intensiva. Um dos possíveis componentes de intangibilidade é a marca. Em termos de causalidade, um aspecto importante a ser estudado, que poderia ser contemplado em estudos futuros, implicaria identificar se o tamanho da empresa é maior em função de uma marca mais forte, mais valorizada, ou se a marca é mais forte em função de um tamanho maior.

\section{REFERÊNCIAS}

AAKER, David A.; JOACHIMSTHALER, Erich. Brand leadership. New York: The Free Press, 2000.

CHAUVIN, K.W.; HIRSCHEY, M. Advertising, R\&D expenditures and the market value of the firm. Financial Management, v. 22, n. 4, p. I28-I40, I993.

COPELAND, Thomas E.; KOLLER, Tim; MURRIN, Jack. Valuation: measuring and managing the value of companies. 2. ed. (University edition). New York: John Wiley \& Sons, I996. 
GEORGE, D.; MALLERY, P. SPSS for Windows step by step: a simple guide and reference, I0.o Update. 3. ed. Boston: Allyn \& Bacon, 2000.

HAIR, J.; ANDERSON, R.; THATAM, R.; BLACK, W. Multivariate data analysis. 5. ed. Prentice Hall, I998.

KAYO, Eduardo Kazuo; TEH, Chang Chuan; KIMURA, Herbert. Ativos intangíveis e criação de valor: o papel das marcas e patentes. In: ENCONTRO DE ESTUDOS EM ESTRATÉGIA, II., 2005, Rio de Janeiro, Anais... 2005.

LEV, Baruch. Intangibles: management, measurement, and reporting. Washington: Brookings, 200I.

MARTINS, Eliseu. Contribuição à avaliação do ativo intangível. I972. Tese (Doutorado em Contabilidade) - Faculdade de Economia, Administração e Contabilidade, Universidade de São Paulo, São Paulo, I972.

MEGNA, P.; KLOCK, M. The impact of intangible capital on tobin's q in the semiconductor industry. American Economic Review, v. 83, n. 2, p. 265-269, I993.

PEREZ, Marcelo M.; FAMÁ, Rubens. Ativos intangíveis e o desempenho empresarial. Revista Contabilidade Q Finanças, n. 40, p. 7-24, 2006.

PINDYCK, Robert S.; RUBINFELD, Daniel L. Microeconomia. São Paulo: Makron Books, I994.

RAPPAPORT, Alfred. Creating shareholder value: a guide for managers and investors. 2. ed. New York: The Free Press, I998.

REILLY, Robert F.; SCHWEIHS, Robert P. Valuing intangible assets. New York: McGrawHill, I999.

STEWART III, G. Bennett. The quest for value. New Jersey: Harper Collins, I999.

VILLALONGA, Belén. Intangible resources, tobin's q, and sustainability of performance differences. Journal of Economic Behavior \& Organization, v. 54, n. 2, p. 205-230, 2004.

\section{TRA M ITAÇ Ã O}

Recebido em 17/05/2004

Aprovado em 31/07/2006 
Copyright of Revista de Administração Mackenzie is the property of Universidade Presbiteriana Mackenzie, RAM-Revista de Administracao Mackenzie and its content may not be copied or emailed to multiple sites or posted to a listserv without the copyright holder's express written permission. However, users may print, download, or email articles for individual use. 